\title{
ADRENOCORTICAL FUNCTION RELATED TO METHOXYFLURANE ANAESTHESIA AND SURGERY IN MAN
}

\author{
T. Oyama, M.D., S. Shibata, M.D., F. Matsumoto, M.D., \\ A. MatsukT, M.D., K. KimuRA, M.D., T. TAKAZAWA, M.D., \\ AND T. KuDO, B.S.
}

\begin{abstract}
ALthough MANY ANAESTHETIC AGENTS have been reported to have some influence on adrenocortical function in man, ${ }^{1-3}$ reports on the effect of methoxyflurane anaesthesia on endocrine organs has been scant. The present investigation was undertaken to study the effects of methoxyflurane anaesthesia and surgery on adrenocortical function by judging its influence on plasma free hydrocortisone (17-hydrocorticosteroid $=17-\mathrm{OHCS}$ ) levels in the peripheral venous blood in man.
\end{abstract}

\section{METHOD}

Eleven patients who underwent the various surgical operations shown in the Table I were studied. Their ages ranged from 19 to 64 years, and none of them had any clinical evidence of endocrine disorder or impaired renal or hepatic function, or had received ACTH or corticosteroid compounds.

Each patient was premedicated with pentobarbital 50-100 mg. orally one and one-half hours prior to the induction of anaesthesia. Atropine $0.5 \mathrm{mg}$. and meperidine $35 \mathrm{mg}$. were injected intramuscularly one and one-quarter hours before the induction of anaesthesia.

Methoxyflurane anaesthesia was induced with inspired concentrations between 0.6 and 1.2 per cent by Pentec vaporizer, combined with $\mathrm{N}_{2} \mathrm{O}(3 \mathrm{~L} . / \mathrm{min}$.) and $\mathrm{O}_{2}(3 \mathrm{~L} . / \mathrm{min}$.) under mask at 8:00-8:30 A.M. After endotracheal intubation following injection of $40 \mathrm{mg}$. of succinylcholine chloride, anaesthesia was maintained with methoxyflurane, $\mathrm{N}_{2} \mathrm{O}\left(3 \mathrm{~L} . / \mathrm{min}\right.$. ) and $\mathrm{O}_{2}(3 \mathrm{~L} . / \mathrm{min}$. $)$.

Controlled or assisted ventilation was carried on throughout the procedure. A moderate depth of anaesthesia was maintained by clinical judgment based on signs including blood pressure, pulse rate, and somatic reflexes in response to the surgical stimuli. The average operating time was two hours and one minute and the average anaesthesia time was three hours and three minutes.

Determination of free 17-OHCS concentration in plasma was made for $1 \mathrm{ml}$. of plasma by Rudd's fluorimetric method ${ }^{4}$ with a Farrand spectrofluorimeter, using an activating wavelength of $470 \mathrm{~m} \mu$ and a fluorescent wavelength of $530 \mathrm{~m} \mu$. Two determinations were made in each plasma sample and the mean value was taken; its duplicate error was $\pm 1.2 \mu \mathrm{g}$. per $100 \mathrm{ml}$. of plasma. This appeared to be reliable for the analysis of our data.

The blood sampling time was as follows: (1) immediately before induction of

-Department of Anaesthesiology, Hirosaki University School of Medicine, Hirosaki, Aomori-Ken, Japan.

Canad. Anaes. Soc. J., vol. 15, no. 4, July 1968 


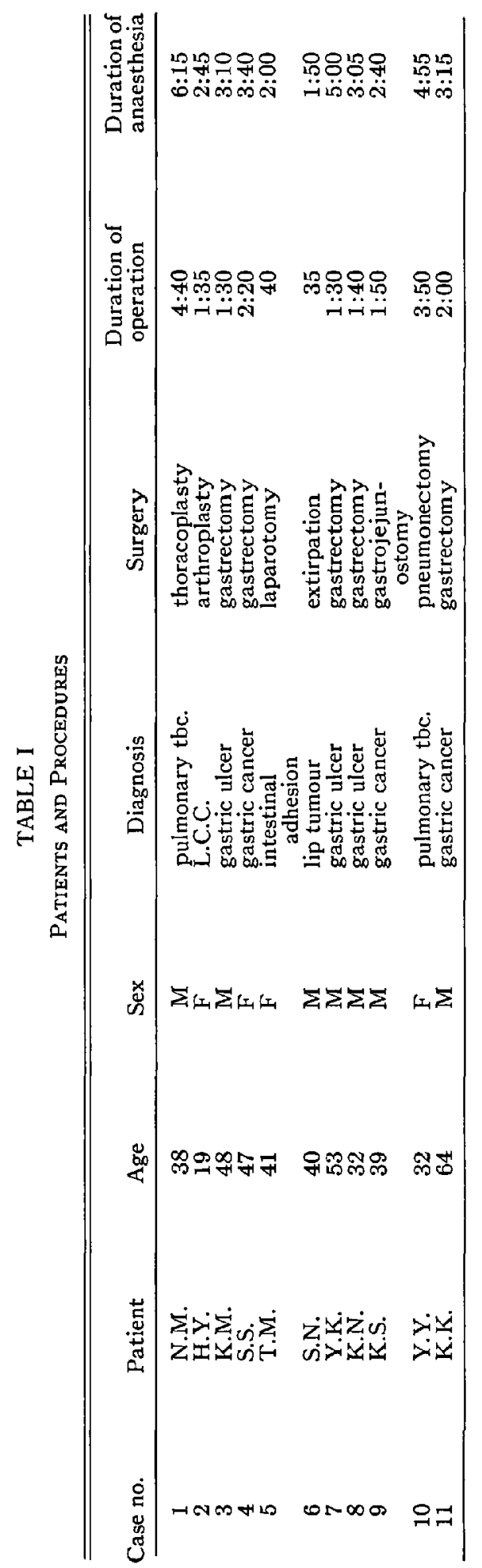


anaesthesia (this sample served as a control value), (2) 30 minutes after methoxyflurane anaesthesia, (3) five minutes after start of surgery, (4) one and two hours after the start of surgery, and (5) in the recovery room. Three millilitres of venous blood was collected on each occasion in a heparinized syringe, rapidly transferred to a tube, then centrifuged within 30 minutes of collection. These plasma samples were kept at $-20^{\circ} \mathrm{C}$. until just prior to analysis.

\section{RESULtS}

\section{Effects of Preanaesthetic Medication}

The mean preanaesthetic concentration of free 17-OHCS in plasma at 8:008:30 A.M. was $13.1 \pm 1.3 \mu \mathrm{g}$. per $100 \mathrm{ml}$. of plasma ( $\pm=$ standard error). This value was significantly lower than the mean value of $18.20 \pm 1.58 \mu \mathrm{g}$. per $100 \mathrm{ml}$. at 8:30 A.M. in our laboratory $(t=4.42, p<0.005)$ in eleven other non-premedicated patients.

\section{Effect of Methoxyflurane Anaesthesia}

The mean presurgical concentration of free 17-OHCS in plasma after 30 minutes of methoxyflurane anaesthesia in the eleven patients was increased by $1.6 \mu \mathrm{g}$. per $100 \mathrm{ml}$. of plasma above the preanaesthetic control level. It increased in five patients, decreased in four patients, and was unchanged in two patients, as illustrated in Table II and Figure 1. This was not statistically significant.

Free 17-OHCS levels increased to an average of $15.9 \pm 2.4 \mu \mathrm{g}$. per $100 \mathrm{ml}$. of plasma within five minutes after skin incision, and this elevation was statistically significant $(t=3.88, p<0.005)$ in comparison with the mean preanaesthetic control level.

\section{During Operation}

Plasma levels of free $17-\mathrm{OHCS}$ rose to $30.2 \pm 2.6 \mu \mathrm{g}$. per $100 \mathrm{ml}$. one hour after the start of surgery. This was a highly significant difference from the mean preanaesthetic control level $(p<0.001)$. The elevation continued two hours after the start of surgery and in the recovery room.

\section{Discussion}

Decrease in plasma hydrocortisone level with preanaesthetic medication was demonstrated in the present study, which confirmed our previous observation. ${ }^{5}$ Our findings would imply that preanaesthetic medication is necessary to reduce emotional and nervous stress in the preoperative period, judged by the suppressing effects on adrenal cortical function.

Mean elevation of plasma hydrocortisone concentration was observed after 30 minutes of methoxyflurane anaesthesia alone. However, this was insignificant in comparison with the mean value of the preinduction control level. The above findings appear to contrast with observations of other anaesthetic agents such as diethyl ether, ${ }^{1-3}$ halothane, ${ }^{5}$ and gamma-hydroxybutyrate, ${ }^{6}$ which significantly increase plasma hydrocortisone levels in man. 


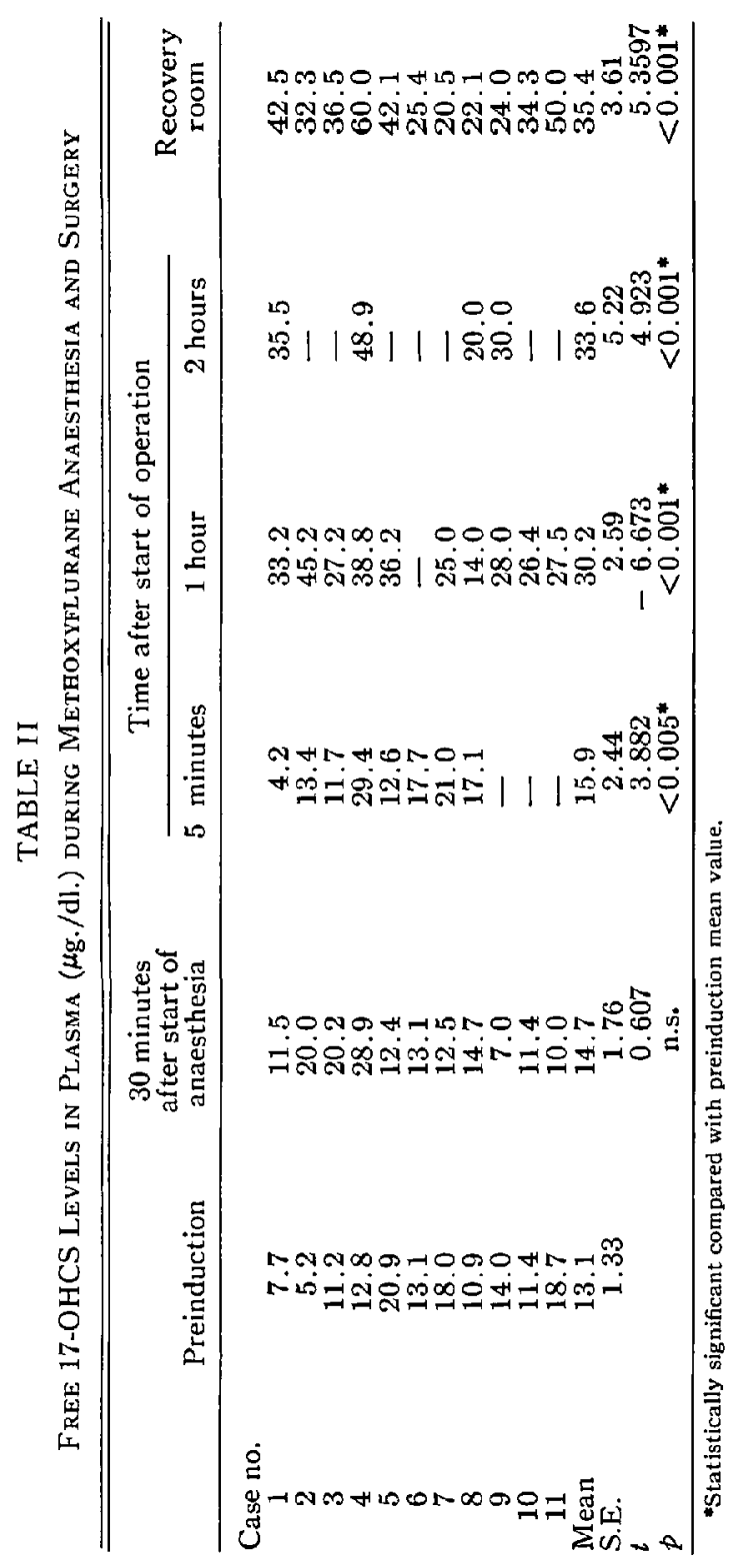




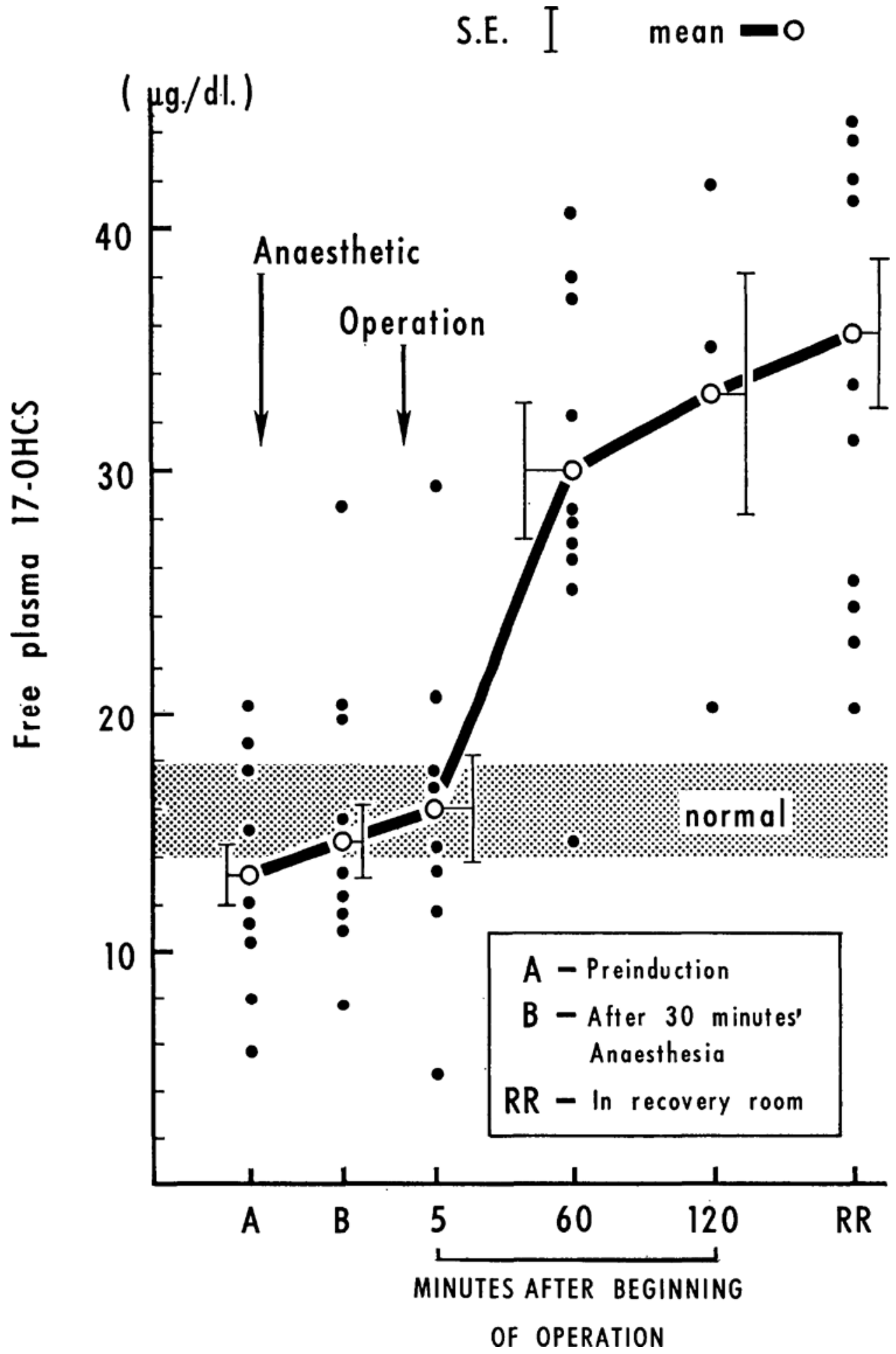

Figure 1. Effects of methoxyllurane- $\mathrm{N}_{2} \mathrm{O}$ anaesthesia on free 17-OHCS concentrations in plasma in man. 
Factors which control the concentration of free hydrocortisone in peripheral blood are (1) the secretion rate of 17-OHCS from the adrenal cortex and (2) the rate of removal of 17-OHCS from the blood as a result of metabolism by the liver and utilization by the tissues. The most important factor to be considered is, of course, the secretion of glucocorticoid from the adrenal cortex.

Hume and Bell ${ }^{7}$ showed that increase of $17-$ OHCS concentrations in the adrenal venous blood accounted for the elevation of 17-OHCS levels in the peripheral venous blood during ether anaesthesia in man. Furthermore, Oyama recently demonstrated that the rise of $\mathrm{ACTH}$ concentration in plasma accounts for the increased free 17-OHCS levels in plasma during ether anaesthesia in man. ${ }^{8}$ Therefore, the observed insignificant effects of methoxyflurane anaesthesia on plasma 17-OHCS levels would imply that methoxyflurane does not stimulate the adrenal cortex in man.

It has been pointed out by others ${ }^{9,10}$ that the metabolism of hydrocortisone in the liver is not handled in the usual manner under surgical stress. Therefore we cannot neglect the influence of the hepatic and renal functions on free hydrocortisone levels in the plasma of peripheral venous blood. However, Estep et al. recently demonstrated that the role of the liver in hydrocortisone metabolism under surgical stress is not so important in healthy patients. ${ }^{11}$

\section{Conclusion and Summary}

The effect of preanaesthetic medication, methoxyflurane anaesthesia, and surgery on free hydrocortisone (= 17-OHCS) concentrations in plasma were studied in eleven patients. The preanaesthetic medication significantly decreased plasma levels of free 17-OHCS, but the changes in concentration were variable after methoxyflurane anaesthesia for 30 minutes. Surgical stress evoked significant elevation of free 17-OHCS levels in plasma. These findings would imply that methoxyflurane anaesthesia is not a stressing agent for the adrenal cortex in man.

\section{RÉSUMÉ}

Nous avons étudié, chez onze malades, l'effet sur l'hydrocortisone libre ( = 17OHCS) dans le plasma produit par la prémédication anesthésique, par l'anesthésie au méthoxyflurane et par la chirurgie.

La prémédication anesthésique a abaissé de façon marquée les taux dans le plasma des 17-hydroxycorticostéroïdes, mais, après une anesthésie de trente minutes au méthoxyflurane, les changements ont été variables. L'agression chirurgicale a produit une élévation importante des taux dans le plasma des 17hydroxycorticostéroïdes.

Ces résultats permettent de supposer que l'anesthésie au méthoxyflurane n'exercerait pas une agression sur le cortex surrénalien de l'homme.

\section{REFERENCES}

1. Virtue, R. W.; Helmrich, M. L.; \& Gainza, E. Adrenal Cortical Response to Surgery: I. The Effect of Anesthesia on Plasma 17-hydrocorticosteroid Levels. Surgery. 41: 549 (1957). 
2. Hammond, W. G.; Vandam, L. D.; Davis, J. M.; Carter, R. D.; Ball, M. R.; \& Moore, F. D. Studies in Surgical Endocrinology: IV. Anesthetic Agents as Stimuli to Change in Corticosteroids and Metabolism. Ann. Surg. 148: 199 (1958).

3. Vandam, L. D. \& MoORE, F. D. Adrenocortical Mechanisms Related to Anesthesia. Anesthesiology. 21: 531 (1960).

4. Rudd, B. T.; Cowper, J. M.; \& CaAwrord, N. The Determination of Plasma Free Hydrocortisone and Corticosterone by a Combined Fluorimetric and Modified Porter-Silber Procedure. Clin. Chim. Acta. 6: 686 (1961).

5. Oyama, T.; Shibata, S.; Matsumoto, F.; \& Kudo, T. Effects of Halothane Anaesthesia and Surgery on Adrenocortical Function in Man. Canad. Anaesth. Soc. J. 15; 258 (1968).

6. - Effects of $\gamma$-Hydroxybutyrate on Adrenocortical Function. Agressologie. 8: 441 (1967).

7. Hume, D. M. \& BeLr, C. C. Secretion of Epinephrine, Norepinephrine and Corticosteroid in Adrenal Venous Blood of the Human. Surg. Forum. 9: 6 (1959).

8. Oyama, T.; Saito, T.; Isomatsu, T.; Samejima, N.; Uemura, T.; \& Arimura, A. Plasma Levels of ACTH and Cortisol in Man during Diethyl-Ether Anesthesia and Surgery. Anesthesiology. 29: 559 (1968).

9. Sandberg, A. A.; EIK-Nes, K.; Samuels, L. T.; \& Tyler, F. H. The Effects of 17Hydroxycorticosteroids in Man. J. Clin. Invest. 33: 1509 (1954).

10. Murray, J. O. S.; Mark, L. J.; Colombo, F. V.; Josephs, B.; Leftin, J. H.; \& Leonard, M. P. The Effect of Surgical Operation on the Plasma Clearance of Infused Cortisol. Ann. Surg. 148: 951 (1958).

11. Estep, H. L.; Litchfield, D. L.; Taylor, J. P.; \& Tucker, H. St. G., Jr. Acute Effect of Traumatic Stress on Cortisol Metabolism in Man. J. Clin. Endocr. 26: 513 (1966). 